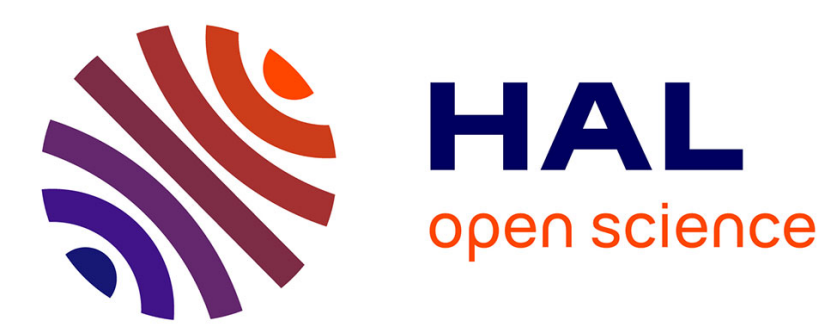

\title{
A passivity-based controller for coordination of converters in a fuel cell system
}

\author{
M. Hilairet, M Ghanes, O. Béthoux, V Tanasa, J-P Barbot, D.
}

Normand-Cyrot

\section{- To cite this version:}

M. Hilairet, M Ghanes, O. Béthoux, V Tanasa, J-P Barbot, et al.. A passivity-based controller for coordination of converters in a fuel cell system. Control Engineering Practice, 2013, 21 (8), pp.1097 1109. 10.1016/j.conengprac.2013.04.003 . hal-00923716v2

\section{HAL Id: hal-00923716 \\ https://hal.science/hal-00923716v2}

Submitted on 2 Mar 2019

HAL is a multi-disciplinary open access archive for the deposit and dissemination of scientific research documents, whether they are published or not. The documents may come from teaching and research institutions in France or abroad, or from public or private research centers.
L'archive ouverte pluridisciplinaire HAL, est destinée au dépôt et à la diffusion de documents scientifiques de niveau recherche, publiés ou non, émanant des établissements d'enseignement et de recherche français ou étrangers, des laboratoires publics ou privés. 


\section{Accepted Manuscript}

A passivity-based controller for coordination of converters in a fuel cell system

M. Hilairet, M. Ghanes, O. Béthoux, V. Tanasa, J-P. Barbot, D. Normand-Cyrot

DOI:

10.1016/j.conengprac.2013.04.00397

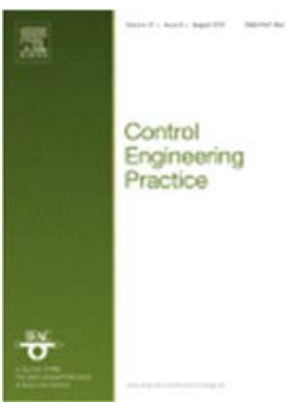

Reference:

Publisher:

ELSEVIER

To appear in:

Control Engineering Practice

Received date: $\quad$ 4 September 2012

Accepted date: $\quad 4$ April 2013

Date of Publication: $\quad$ Available online 14 May 2013 (Volume 21, n 8, Pages 1097-1109)

Prize for 2011-13 of the three best papers

Please cite this article as: M. Hilairet, M. Ghanes, O. Béthoux, V. Tanasa, J-P. Barbot, D. Normand-Cyrot, A passivity-based controller for coordination of converters in a fuel cell system, Control Engineering Practice, Volume 21, Issue 8, August 2013, Pages 1097-1109, DOI: 10.1016/j.conengprac.2013.04.003.

Document Version: $\quad$ Early version, also known as pre-print

This is a PDF file of an unedited manuscript that has been accepted for publication. As a service to our customers we are providing this early version of the manuscript. The manuscript will undergo copyediting, typesetting, and review of the resulting proof before it is published in its final form. Please note that during the production process errors may be discovered which could affect the content, and all legal disclaimers that apply to the journal pertain. 


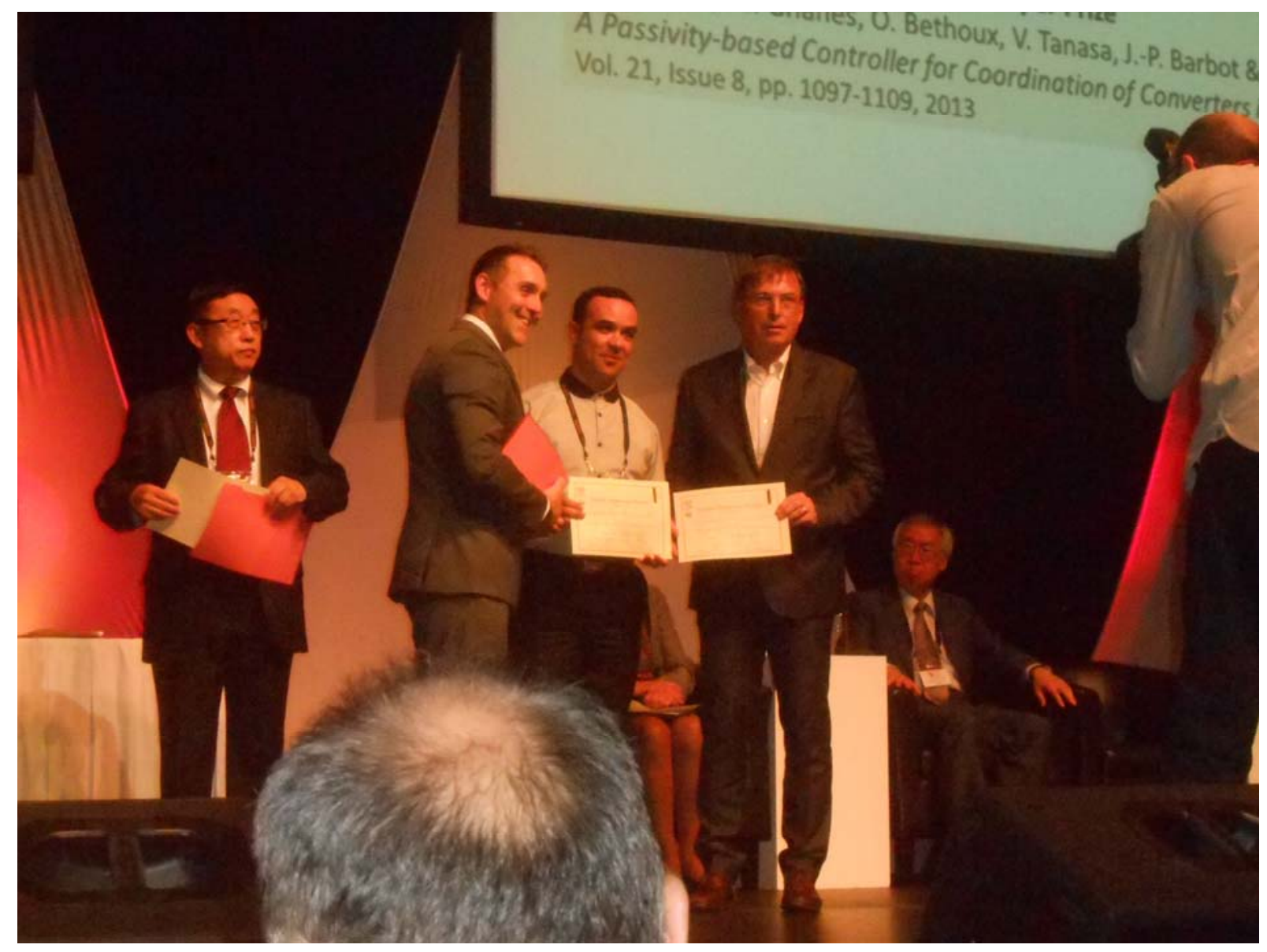




\title{
A Passivity-Based Controller for coordination of converters in a Fuel Cell System
}

\author{
M. Hilairet ${ }^{\mathrm{a}}$, M. Ghanes ${ }^{\mathrm{b}}$, O. Béthoux ${ }^{\mathrm{c}}$, V. Tanasa ${ }^{\mathrm{d}}$, J-P. Barbot ${ }^{\mathrm{b}}$, D. Normand-Cyrot $^{\mathrm{d}}$ \\ ${ }^{a}$ FEMTO-ST/FCLab, CNRS UMR 6174, Université de Franche-Comté, F-90010 Belfort, France \\ ${ }^{b}$ ECS-Lab/ENSEA, 6 Avenue du Ponceau, 95014 Cergy-Pontoise, France \\ ${ }^{c}$ LGEP/SPEE Labs; CNRS UMR850\%; SUPELEC; Univ Pierre et Marie Curie-P6; Univ Paris Sud-P11, \\ 91192 Gif sur Yvette, France \\ ${ }^{d}$ Laboratoire des Signaux et Systèmes; CNRS UMR 8506; SUPELEC; Université Paris-Sud 11; \\ 3, rue Joliot Curie, Plateau de Moulon F91192 Gif sur Yvette \\ e-mail: mickael.hilairet@univ-fcomte.fr
}

\begin{abstract}
The problem of converters coordination of a fuel cell system involving a hydrogen fuel cell with supercapacitors for applications with high instantaneous dynamic power is addressed in this paper. The problem is solved by using a non-linear controller based on passivity. The controller design is based on the interconnection and damping assignment approach, where the proof of the local system stability of the whole closed-loop system is shown. Simulation and experimental results on a reduced scale system prove the feasibility of the proposed approach for a real electrical vehicle.
\end{abstract}

Keywords: Fuel cell, supercapacitors, power management, port-controlled Hamiltonian systems, IDA-PBC methodology, experimentation.

\section{Introduction}

To comply with environmental norms, the development of electric and hybrid vehicles has increased since 2009. In this context, the development of a fuel cell (FC) system as the main source of energy, is considered due to the noise reduction, high efficiency, low weight, compact size, modularity and controllability. However, this technology has some weak points, such as cost, reliability and durability. Specifically, to ensure a good health state of the FC, it is necessary for the FC to deliver a slowly varying current, i.e. a current slope lower than $4 \mathrm{~A} / \mathrm{s}$ for a $0.5 \mathrm{~kW} / 12.5 \mathrm{~V} \mathrm{FC}$ (Thounthong, Rael and Davat, 2009), and 
$10 \mathrm{~A} / \mathrm{s}$ for a $20 \mathrm{~kW} / 48 \mathrm{~V}$ FC (Corbo, Migliardinia and Veneri, 2009a) as examples. Thus, an FC needs to be associated with other sources which supply short pulse energy and fill the temporary failure of the FC (Hissel et al., 2008). Nowadays, these auxiliary sources can either be batteries or supercapacitors (SCs) Sometimes, batteries are not able to bear high power charge and discharge conditions, whereas supercapacitors have a high power range. Therefore, for fast power demands, supercapacitors are probably the best-suited components (Rodatz et al., 2005).

In this paper, the challenging problem of the power management of an hydrogen FC system associated to a reversible impulse energy source (the supercapacitors) is considered and involves both practical and theoretical issues. There are several electric architectures of the hybrid system, which can be classified into three categories : series, cascaded and parallel (Jiang et al., 2004; Cacciato et al., 2004). The literature has shown that the parallel architectures are the most suitable ones.

The parallel structures with only one converter (Azib et al., 2010; Davat et al., 2009) or two converters (Davat et al., 2009) can fully respect the mentioned requirements. This paper is dedicated to the study of the structure with two converters as shown in Fig. 1.

Nowadays, high-performance and efficiency controllers are readily available (Vahidi, Stefanopoulou and Peng, 2006; Thounthong, Rael and Davat, 2009; Thounthong et al., 2009b; Azib et al., 2009a,b; Arce, del Real and Bordons, 2009). These allow to the current, delivered by the FC, to have smooth behavior in order to ensure its life time, while the SCs provide

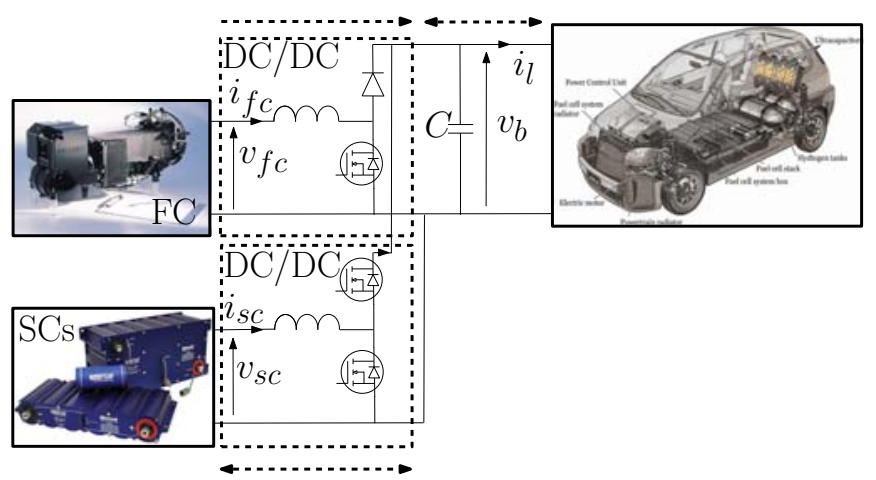

Figure 1: Two converters parallel structure studied in this work. 
the load power transient (Arce, del Real and Bordons, 2009; Thounthong et al., 2009b). Unfortunately, the closed-loop system stability of these controllers are generally not proved theoretically, although they are effective.

Therefore, this drawback opens a theoretically challenging problem. In this work, a non-linear controller based on the Interconnection and Damping Assignment - Passivity Based Control (IDA-PBC) has been studied in order to prove the local asymptotic stability of the whole closed-loop system, while maintaining the same objectives and components security as standard controllers, i.e. the controller has to sustain the bus voltage and the supercapacitors voltage at desired levels without compromising the FC operation as the fuel starvation during fast load change which refers to an operation with an insufficient amount of gas in the active layer (Yousfi-Steiner et al., 2009).

This paper is divided into four sections as follows: section two describes some standard power management controllers based on a frequency decoupling of the sources. The proposed passivity-based controller is detailed in section three; in section four simulation results are presented. Finally, the approach has been applied to a reduced scaled test bench system based on the Nexa Ballard fuel cell. Furthermore, section V deals with the implementation and experimental results.

\section{Power management}

The power management must comply with the load power demands and to provide an effective fuel cell control while decreasing the fuel consumption. Also it has to prevent the fuel starvation during fast load demands, to maintain the DC bus and state of charge of the supercapacitors constant and to ensure the proper use of each component.

The main objective of the control strategies is to regulate the DC bus voltage with the FC as the primary power source (Davat et al., 2009). However, fuel cell performances (efficiency, degradation, aging effects) are influenced by many environmental and application constraints (Wahdame et al., 2008). These aging tests prove that limiting the load dynamic effects can save the FC performances and raise its durability. Therefore, it seems clear that the DC bus regulation has to be managed by the supercapacitors. A short survey reveals a significant 
number of strategies, like the one based on the state-feedback (Jiang et al., 2004), fuzzy logic (Kisacikoglu, Uzunoglu and Alam, 2009; Martinez et al., 2011), proportional-integral controllers (Azib et al., 2010), RST controller (Caux et al., 2005), passivity (Becherif, 2006), flatness (Zandi et al., 2011) or model predictive control (Vahidi, Stefanopoulou and Peng, 2006). Alternative approach exist such as optimal control (Rodatz et al., 2005), dynamic programming (Brahma, Guezennec and Rizzoni, 2000) or empirical control associated with a multi objective genetic algorithm optimization (Paladini et al., 2007) that has been applied for the supervisory power train control problem in charge sustaining hybrid electric vehicles. However, these approaches are based on the a priori knowledge of the power load, thus real-time control is not straightforward implementable.

In (Azib et al., 2011), a two converters structure control strategy has been detailed. It relies on the control of the converter in such a way to split the demanded power between the FC and SCs. The converter-parameter tuning is based on a frequency decoupling so that to coordinate the two sources without compromising the FC operation. The DC bus capacitor filters the high frequencies (i.e. above the $\mathrm{kHz}$ ), the SCs associated with their converters provide the medium frequencies (from $1 \mathrm{kHz}$ to $1 \mathrm{~Hz}$ ), and the $\mathrm{FC}$ ensures the low frequencies (less than $1 \mathrm{~Hz}$ ). This frequency decoupling of the sources naturally induces a power management strategy based on cascaded loops and the control is effective (Azib et al., 2011). The gains are tuned to ensure the closed-loop system stability, although it has not been theoretically proved. Therefore, this drawback seems to be a theoretically challenging problem, while maintaining the same objectives and the component security. Therefore, in this work a passivity-based controller, which relies on the well-known IDA-PBC method (Ortega et al., 2002; Ortega and Garcia-Canseco, 2004; Ortega et al., 2008), has been studied in order to prove the asymptotic stability of the outer closed-loop system and finally the local asymptotic stability of the whole system.

In (Becherif, 2006) a full order IDA-PBC has been designed for a similar system. However, currents $i_{f c}$ and $i_{s c}$ can exceed the maximum value allowed, because they are not directly controlled. This point is generally mandatory for industrial applications; it is the reason why the strategy proposed in this paper comprises two loops as shown in Fig. (2). To 
be more precise, there are two inner current loop controllers for the FC and SCs respectively, based on PI controllers and only one outer loop which controls the DC bus voltage and state of charge of the SCs. In this work, the outer-loop controller is based on passivity approach.

\section{Passivity-based controller}

\subsection{Port controlled Hamiltonian system}

The PBC defines a controller design methodology that stabilizes the system by making it passive. Although there are many variations on this basic idea, the PBC can be broadly classified into two major groups. In the "regular" PBC, the designer chooses the storage function (usually quadratic), and then designs the controller that makes the storage function non-increasing (Cecati et al., 2003). In the second PBC methodology, the storage function of the closed-loop system remains free. The designer selects a control structure, such as Lagrangian, port-controller Hamiltonian $(\mathrm{PCH})$ or Brayton-Moser formulation (Weiss, Mathis and Trajkovic, 1998; Jeltsema and Scherpen, 2003; Zhou, Khambadkone and Kong, 2009), and then, characterizes all assignable energy or power functions. The most notable examples of this approach are the controlled Lagrangian systems, and the IDA-PBC (Van der Schaft, 1996; Ortega et al., 2002; Ortega and Garcia-Canseco, 2004; Ortega et al., 2008). It is the latter method that has been chosen in this work.

Firstly, the IDA-PBC approach consists in identifying the natural energy function of the system called $H(x)$. Rewriting a non-linear system:

$$
\begin{aligned}
\dot{x} & =f(x)+g(x) u ; & x \in \Re^{n} ; u \in \Re^{m} \\
y & =h(x) ; & y \in \Re^{m}
\end{aligned}
$$

versus the gradient of the energy function:

$$
\nabla H(x)=\left[\begin{array}{llll}
\frac{\partial H}{\partial x_{1}}(x) & \frac{\partial H}{\partial x_{2}}(x) & \ldots & \frac{\partial H}{\partial x_{n}}(x)
\end{array}\right]^{T}
$$

leads to PCH form as follows:

$$
\begin{aligned}
\dot{x} & =[\mathcal{J}(x)-\mathcal{R}(x)] \mathcal{H}(x)+g(x) u \\
y & =g^{T}(x) \nabla H(x)
\end{aligned}
$$


where $y$ is the output, $\mathcal{J}(x)=-\mathcal{J}^{T}(x)$ is a skew-symmetric matrix of dimension $n \times n$ representing the interconnections between states, and $\mathcal{R}(x)=\mathcal{R}^{T}(x) \geq 0$ is a positive semi-definite symmetric matrix representing the natural damping of the system.

\subsection{The IDA-PBC Methodology}

Let us consider the system (Ortega and Garcia-Canseco, 2004; Ortega et al., 2008)

$$
\dot{x}=f(x)+g(x) u
$$

and assume there are matrices $\mathcal{J}_{d}(x)=-\mathcal{J}_{d}^{T}(x), \mathcal{R}_{d}(x)=\mathcal{R}_{d}^{T}(x) \geq 0$ and a function $H_{d}(x): \Re^{n} \longrightarrow \Re$ so that the closed-loop system (1) with control variable $u$

$$
u=\left[g^{T}(x) g(x)\right]^{-1} g^{T}(x)\left\{\left[\mathcal{J}_{d}(x)-\mathcal{R}_{d}(x)\right] \nabla H_{d}-f(x)\right\}
$$

takes the $\mathrm{PCH}$ form

$$
\dot{x}=\left[\mathcal{J}_{d}(x)-\mathcal{R}_{d}(x)\right] \nabla H_{d}
$$

$H_{d}(x)$ is such that $x^{*}=\operatorname{argmin}_{\mathrm{x} \in \Re^{\mathrm{n}}}\left(\mathrm{H}_{\mathrm{d}}(\mathrm{x})\right)$ with $x^{*} \in \Re^{n}$ the (locally) equilibrium to be stabilized. The system is asymptotically stable if, in addition, $x^{*}$ is an isolated minimum of $H_{d}(x)$ and if the largest invariant set under the closed-loop dynamics (2) contained in $\left\{x \in \Re^{n} \mid\left[\nabla H_{d}\right]^{T} \mathcal{R}_{d}(x) \nabla H_{d}=0\right\}$ equals $x^{*}$.

The stability of $x^{*}$ is established noting that, along the trajectories of (2), we have

$$
\dot{H}_{d}=-\left[\nabla H_{d}\right]^{T} \mathcal{R}_{d}(x) \nabla H_{d} \leq 0
$$

Hence, $H_{d}(x)$ is qualified as a Lyapunov function. Asymptotic stability immediately follows invoking the La Salle's invariance principle (LaSalle, 1960). Finally, to ensure that the solutions remain bounded, we give the estimate of the field of attraction as the largest bounded level set of $H_{d}(x)$.

\subsection{Hybrid system modeling}

Fuel cell modeling. The model used is a static model (Pukrushpan, Peng and Stefanopoulou, 2004) where the FC voltage $v_{f c}$ is computed according to the current stack $i_{f c}$ by a $5^{\text {th }}$ order polynomial function as shown in Fig. (3). The data fitting has been obtained according to experimental results. 
SCs boost converter. SCs can be charged or discharged; therefore the storage elements are connected to the DC bus through a reversible power converter as shown in Fig. (4). The boost converter is controlled by binary input $w_{2}(t)$. We define $\alpha_{2}$ as the duty cycle of the control variable $w_{2}(t)$. The second sub-system is represented by an average model as follows

$$
\begin{aligned}
\frac{d}{d t} i_{s c}(t) & =\frac{1}{L_{s c}}\left(-\left(1-\alpha_{2}(t)\right) v_{b}(t)+v_{s c}(t)\right) \\
\frac{d}{d t} v_{s c}(t) & =-\frac{i_{s c}(t)}{C_{s c}}
\end{aligned}
$$

FC boost converter, DC bus and load model. To use the FC in an electric power system, a boost converter must increase the $\mathrm{FC}$ voltage, because the $\mathrm{FC}$ voltage is often less than the DC bus voltage. The boost converter represented in Fig.(4) is controlled by binary input $w_{1}(t)$. Defining $\alpha_{1}$ as the duty cycle of control variable $w_{1}(t)$, this subsystem can be represented by its average model (here, the switches are regarded as ideal) :

$$
\begin{aligned}
\frac{d}{d t} i_{f c} & =\frac{1}{L_{f c}}\left(-\left(1-\alpha_{1}(t)\right) v_{b}(t)+v_{f c}(t)\right) \\
\frac{d}{d t} v_{b}(t) & =\frac{1}{C}\left(\left(1-\alpha_{1}(t)\right) i_{f c}(t)+\left(1-\alpha_{2}(t)\right) i_{s c}(t)-i_{l}(t)\right)
\end{aligned}
$$

where $v_{b}(t)$ is the $\mathrm{DC}$ link voltage, $v_{f c}(t)$ is the $\mathrm{FC}$ voltage, $i_{l}(t)$ is the $\mathrm{DC}$ current delivered to the load and $i_{f c}(t)$ is the $\mathrm{FC}$ current.

In our work, the load is modeled by a variable resistance circuit $\left(R_{l}(t)\right)$, whose value varies according to the power required by the load. The average model is:

$$
\frac{d}{d t} i_{l}(t)=\frac{1}{L}\left(-R_{l}(t) i_{l}(t)+v_{b}(t)\right)
$$

where inductance $L$ is not part of the load and represents the imperfections of the system. The load model could have been replaced by a current source $i_{l}(t)$ and the same approach described later could be adopted (see appendix 3).

Complete model. It follows that the complete "fuel cell - supercapacitors" system is represented by the $5^{\text {th }}$ order non-linear state space model : 


$$
\begin{aligned}
\frac{d}{d t} v_{b}(t) & =\frac{\left(1-\alpha_{1}(t)\right) i_{f c}(t)+\left(1-\alpha_{2}(t)\right) i_{s c}(t)-i_{l}(t)}{C} \\
\frac{d}{d t} v_{s c}(t) & =-\frac{i_{s c}(t)}{C_{s c}} \\
\frac{d}{d t} i_{l}(t) & =\frac{-R_{l}(t) i_{l}(t)+v_{b}(t)}{L} \\
\frac{d}{d t} i_{f c}(t) & =\frac{-\left(1-\alpha_{1}(t)\right) v_{b}(t)+v_{f c}(t)}{L_{f c}} \\
\frac{d}{d t} i_{s c}(t) & =\frac{-\left(1-\alpha_{2}(t)\right) v_{b}(t)+v_{s c}(t)}{L_{s c}}
\end{aligned}
$$

with state space $x(t)=\left[v_{b} ; v_{s c} ; i_{l} ; i_{f c} ; i_{s c}\right]^{T}$, control inputs $u(t)=\left[u_{1} ; u_{2}\right]^{T}=\left[1-\alpha_{1} ; 1-\right.$ $\left.\alpha_{2}\right]^{T}$, measures $y(t)=x$ and $v_{f c}$.

Outer loop model (reduced model). The system of 5 equations (3 to 7 ) is called a singular perturbed system, because of the difference of time scale between the voltages and the currents (Kokotovi et al., 1986). Therefore, the system (3 to 7) is forced into current-controlled mode using a fast inner current loop. More precisely, the following PI current controllers associated with a anti-windup scheme

$$
\begin{gathered}
u_{1}=K i_{f c} \int_{0}^{t}\left(i_{f c}^{*}-i_{f c}\right) d t+K p_{f c}\left(i_{f c}^{*}-i_{f c}\right) \\
u_{2}=K i_{s c} \int_{0}^{t}\left(i_{s c}^{*}-i_{s c}\right) d t+K p_{s c}\left(i_{s c}^{*}-i_{s c}\right)
\end{gathered}
$$

are used to force $i_{f c}$ and $i_{s c}$ to track their respective references $i_{f c}^{*}$ and $i_{s c}^{*}$ and produce fast responses when large feedback gains are used. The control $u_{1}$ and $u_{2}$ act as high-gain feedback, for more details see for example (Marino , 1985).

Consider (6) and (8) for $K i_{f c}$ and $K p_{f c}$ sufficiently large with respect to voltage and load dynamics. After transient (convergence), one get $i_{f c}-i_{f c}^{*}=0$ and $\int_{0}^{t}\left(i_{f c}^{*}-i_{f c}\right)=\frac{v_{f c}}{v_{b} K i_{f c}}$. These imply that (8), after transient, becomes $u_{1}=\frac{v_{f c}}{v_{b}}$. The same argument is used for (7) and (9), where after transient, one get $u_{2}=\frac{v_{s c}}{v_{b}}$. Consequently after transient, by replacing the new obtained $u_{1}$ and $u_{2}$ in (3), and currents $i_{f c}-i_{s c}$ by their references $i_{f c}^{*} i_{s c}^{*}$ in (3) and (4) as a new inputs, it follows that

$$
\begin{aligned}
\frac{d}{d t} v_{b}(t) & =\frac{1}{C}\left(\frac{v_{f c}(t)}{v_{b}(t)} i_{f c}^{*}(t)+\frac{v_{s c}(t)}{v_{b}(t)} i_{s c}^{*}(t)-i_{l}(t)\right) \\
\frac{d}{d t} v_{s c}(t) & =-\frac{i_{s c}^{*}(t)}{C_{s c}} \\
\frac{d}{d t} i_{l}(t) & =\frac{-R_{l}(t) i_{l}(t)+v_{b}(t)}{L} \\
8 &
\end{aligned}
$$


with $x_{r}(t)=\left[x_{1} ; x_{2} ; x_{3}\right]^{T}=\left[v_{b} ; v_{s c} ; i_{l}\right]^{T}$, control inputs $u_{r}=\left[i_{f c}^{*} ; i_{s c}^{*}\right]^{T}$, measures $y_{r}$ and $z_{r}$ as $y_{r}=\left[v_{b} ; v_{s c} ; i_{l}\right]^{T}$ and $z_{r}=\left[i_{f c} ; i_{s c} ; v_{f c}\right]^{T}$.

Remark 1: In the sequel, the outer closed-loop control is designed by using the model (10) such that its dynamic is slower than the dynamic of the PI fast actuators (8-9).

\subsection{IDA-PBC outer loop controller design}

The main objective of IDA-PBC is to assign the state point $x_{r}=\left[x_{1} ; x_{2} ; x_{3}\right]^{T}=$ $\left[v_{b} ; v_{s c} ; i_{l}\right]^{T}$ to the desired equilibrium one $x_{r}^{*}=\left[v_{b}^{*} ; v_{s c}^{*} ; \frac{v_{b}^{*}}{R_{l}}\right]$, with $v_{b}^{*}$ and $v_{s c}^{*}$ the DC bus and SCs desired voltages, by tacking into account the following constraint and protection:

- Constraint 1 : the FC has to prevent stack stresses during power transients.

- Protection 1 : the FC voltage $v_{f c}$ has to be no less than a minimum value $v_{f c m i n}$.

According to section (3.2), the IDA-PBC methodology looks for an energy function $H_{d}$ so that its minimum is reached at the desired equilibrium point $x_{r}^{*}$. This energy function $H_{d}$ is chosen as $H_{d}=\frac{1}{2}{\tilde{x_{r}}}^{T} Q \tilde{x_{r}}$ with $\tilde{x}_{r}=x_{r}-x_{r}^{*}$ and $Q=\operatorname{diag}\left(\mathrm{C}, \mathrm{C}_{\mathrm{sc}}, \mathrm{L}\right)$. In these circumstances, writing the PCH system in terms of the dynamics of the error and the gradient of desired closed-loop energy function $\nabla H_{d}$ is:

$$
\dot{\tilde{x}}_{r}=[\mathcal{J}-\mathcal{R}] \nabla H_{d}+A\left(u_{r}, x_{r}, x_{r}^{*}, z_{r}\right)
$$

with

$$
\begin{aligned}
\mathcal{J}-\mathcal{R} & =\left[\begin{array}{ccc}
0 & 0 & -\frac{1}{L C} \\
0 & 0 & 0 \\
\frac{1}{L C} & 0 & -\frac{R_{l}}{L^{2}}
\end{array}\right], \quad \nabla H_{d}=\left[\begin{array}{c}
C \tilde{v}_{b} \\
C_{s c} \tilde{v}_{s c} \\
L \tilde{i}_{l}
\end{array}\right] \\
A^{t} & =\left[\frac{1}{C}\left(\frac{v_{f c}}{v_{b}} i_{f c}^{*}+\frac{v_{s c}}{v_{b}} i_{s c}^{*}-i_{l}^{*}\right) ;-\frac{1}{C_{s c}} i_{s c}^{*} ; 0\right]
\end{aligned}
$$

Solving the algebraic equation in $\mathcal{J}_{d}(x)$ and $\mathcal{R}_{d}(x)$ with the constraint of skew-symmetry and positive semi-definiteness of $\mathcal{J}_{d}(x)$ and $\mathcal{R}_{d}(x)$ respectively, with the two unknown matrices equal to:

$$
\mathcal{J}_{d}=\left[\begin{array}{ccc}
0 & J_{12} & J_{13} \\
-J_{12} & 0 & J_{23} \\
-J_{13} & -J_{23} & 0
\end{array}\right], \quad \mathcal{R}_{d}=\left[\begin{array}{ccc}
r_{1} & 0 & 0 \\
0 & r_{2} & 0 \\
0 & 0 & r_{3}
\end{array}\right]
$$


leads to the matching equations:

$$
\begin{aligned}
& -r_{1} C \tilde{v}_{b}+J_{12} C_{s c} \tilde{v}_{s c}+J_{13} L \tilde{i}_{l}=-\frac{1}{C} \tilde{i}_{l}+\frac{1}{C}\left(\frac{v_{f c}}{v_{b}} i_{f c}^{*}+\frac{v_{s c}}{v_{b}} i_{s c}^{*}-i_{l}^{*}\right) \\
& -J_{12} C \tilde{v}_{b}-r_{2} C_{s c} \tilde{v}_{s c}+J_{23} L \tilde{i}_{l}=-\frac{1}{C_{s c}} i_{s c}^{*} \\
& -J_{13} C \tilde{v}_{b}-J_{23} C_{s c} \tilde{v}_{s c}-r_{3} L \tilde{i}_{l}=\frac{1}{L} \tilde{v}_{b}-\frac{R_{l}}{L} \tilde{i}_{l}
\end{aligned}
$$

One solution is $r_{3}=\frac{R_{l}}{L_{l}^{2}}, J_{13}=-\frac{1}{C L}$, and $J_{23}=0$ with $r_{1}>0$ and $J_{12}<0$, which leads to the non-linear control law:

$$
\begin{aligned}
i_{f c}^{*} & =\frac{v_{b}}{\max \left\{\mathrm{v}_{\mathrm{fc}}, \mathrm{v}_{\mathrm{fcmin}}\right\}}\left(\frac{v_{b}^{*}}{R_{l}}+C_{s c}\left(C J_{12}-\frac{v_{s c}}{v_{b}} C_{s c} r_{2}\right) \tilde{v}_{s c}-C\left(\frac{v_{s c}}{v_{b}} C_{s c} J_{12}+r_{1} C\right) \tilde{v}_{b}\right) \\
i_{s c}^{*} & =C_{s c}\left(C J_{12} \tilde{v}_{b}+r_{2} C_{s c} \tilde{v}_{s c}\right)
\end{aligned}
$$

so that the closed-loop system responds to the following dynamics:

$$
\dot{\tilde{x}}_{r}=\left[\mathcal{J}_{d}-\mathcal{R}_{d}\right] \nabla H_{d}
$$

with

$$
\mathcal{J}_{d}=\left[\begin{array}{ccc}
0 & J_{12} & -\frac{1}{L C} \\
-J_{12} & 0 & 0 \\
\frac{1}{L C} & 0 & 0
\end{array}\right], \mathcal{R}_{d}=\left[\begin{array}{ccc}
r_{1} & 0 & 0 \\
0 & r_{2} & 0 \\
0 & 0 & \frac{R_{l}}{L^{2}}
\end{array}\right]
$$

The analysis of the control (12)-(13) shows that SCs supply energy due to an error on the DC bus voltage; the error itself is caused by power spikes or a variation of the DC bus voltage reference. The desired FC current $\left(i_{f c}^{*}\right)$ shows that the FC supply satisfies two main objectives :

- the permanent power flow from the FC to the load,

- the energy contribution to regulate the SCs voltage.

Obviously, it does not seem judicious that the FC current participates in the control of the DC bus voltage according to constraint 1 . So, tuning parameters $r_{1}$ and $J_{12}$ are set equal to $\frac{x_{2} \alpha}{x_{1} C^{2}}$ and $-\frac{\alpha}{C C_{s c}}$ with $\alpha>0$, such that the right hand side of (12) is canceled. 
Moreover, in order that the ultra-capacitors managed only the DC bus voltage as the control proposed in (Azib et al., 2010), the tuning parameter $r_{2}$ is set equal to zero. The control law is now as follows:

$$
\begin{aligned}
i_{f c}^{*} & =\frac{v_{b}}{\max \left\{\mathrm{v}_{\mathrm{fc}}, \mathrm{v}_{\mathrm{fcmin}}\right\}}\left(\frac{v_{b}^{*}}{R_{l}}-\alpha \tilde{v}_{s c}\right) ; \quad \alpha>0 \\
i_{s c}^{*} & =-\alpha \tilde{v}_{b}
\end{aligned}
$$

In practice the fuel cell (FC) voltage $v_{f c}$ is always positive and does not reach zero voltage for safety conditions. Moreover, controllers (12) and (15) are not singular for $v_{f_{c}}$ equal to zero thanks to protection 1.

The proof of the global asymptotic stability of the outer loop (voltage control) is deduced from the derivative analysis of $H_{d}$ equal to $\nabla H_{d}^{T} \dot{\tilde{x}}=-\nabla H_{d}^{T} R_{d} \nabla H_{d}^{T} \leq 0$ and the invariance principle of the LaSalle theorem with $H_{d}\left(x^{*}\right)=\dot{H}_{d}\left(x^{*}\right)=0$. Moreover, $H_{d}$ is radially unbounded; therefore the outer closed-loop system is globally asymptotically stable.

Finally, following high-gain feedback methodology (Marino , 1985), with an appropriate (sufficiently large) choice of the gains $K i_{f c}, K p_{f c}, K i_{f s c}$ and $K p_{s c}$ in (8) and (9), the variable $\eta_{1} \triangleq \int\left(i_{f c}^{*}-i_{f c}\right), \eta_{2} \triangleq i_{f c}^{*}-i_{f c}, \eta_{3} \triangleq \int\left(i_{s c}^{*}-i_{s c}\right)$, and $\eta_{4} \triangleq i_{s c}^{*}-i_{s c}$ are fast states, with respect to others system states, and converge very rapidly on the so-called invariant-manifold (Vasil'eva, A.B. , 1963). As the behavior on the so-called boundary layer is exponentially stable (i.e. in this case the fast dynamic $\dot{\eta}$ is linear) according to the Tikhonov's theorem (Tikhonov, Vasil'eva and V.M. Volosov, 1970), we conclude that the whole system is locally asymptotically stable.

\section{Simulation results}

(15) shows that for the implementation of the proposed controller, the knowledge of the load resistance $\left(R_{l}\right)$ is needed for the computation of the FC reference current. To explain the design procedure, the case for which the load resistance $\left(R_{l}\right)$ is unknown is first considered. In a second case step, a load resistance estimator scheme or an integral action are 
added in order to consider the load variation.

Remark 2: In a practical application, when the controller is implemented by a computer, the system is placed in a sampled-data context. Consequently, the passivity based controller has been simulated and implemented through a zero order holder device (emulation process) with a sampling-time equal to $500 \mu \mathrm{s}$.

\subsection{The case of a unknown parameter}

Fig. (5) represents a scenario where the reference DC bus voltage is set equal to $50 \mathrm{~V}$ and the load current varies between 0 and $15 \mathrm{~A}$. This power cycle is representative of a reduced-scale vehicle power demand, where the load requirement consists in raising and lowering power edges between 0 and $750 \mathrm{~W}$. Here, the load resistance $\left(R_{l}\right)$ is considered as a fixed parameter (the arbitrary admittance used in the controller equation is equal to $5 \mathrm{~A} / 50 \mathrm{~V}=0.1 \mathrm{~S})$. The control strategy provides an insufficient FC current reference during the time interval $[21,101] \mathrm{s}$ and consequently, the SCs provide most of the power during the high power transient and do not recover their equilibrium points, despite the fact that the FC current transient is good.

To cope with this problem, two solutions are explored. In the first one, an estimate of the load resistance is added to the command value $i_{f c}^{*}$, while in the second approach, a low integrator action eliminates this error.

\subsection{IDA-PBC controller + load resistance estimator}

In this paragraph an estimator of the load impedance $Y_{l}=1 / R_{l}$ is considered to deal with this problem, as follow:

$$
\hat{Y}_{l}=\frac{K_{R l}}{s+K_{R l}} \cdot \frac{i_{l k}}{v_{b k}}
$$

where the tuning parameter $K_{R l}$ control the sensibility of the fuel cell current reference. Fig. (6) shows the estimator behavior. In this application, $K_{R l}$ has been selected in order to obtain a slow time response of about $6 \mathrm{~s}$, so that the FC current reference reacts smoothly. 
Fig. (7) depicts the global system performances. In this simulation the load resistance estimate is used in the controller. With the former estimator parameter set $\left(K_{R l}=0.5\right)$, the $\mathrm{FC}$ current variation is less than $4 \mathrm{~A} / \mathrm{s}$. It indeed respects the $\mathrm{FC}$ specifications. This controller architecture also leads to a nearly zero static error of the SCs voltage without adding any integral action. Nevertheless, a low integral action needs to be added in a practical application to compensate for the converter losses.

Remark 4: The proof of the global stability of the system composed of the controller, the estimator and electrical sub-system (10) invoking a theorem on stability of cascaded systems stated in (Panteley and Loria, 1998) can be found in appendix 2.

\subsection{IDA-PBC controller + integral action}

The controller design supposes that the converters are loss-less. So in practice, a low integrator action needs to be added to the passivity controller in order to ensure zero SCs voltage error at steady state and to counteract the unknown load resistance consequences (Donaire and Junco, 2009). The controller equations are now:

$$
\begin{aligned}
\dot{u}_{i} & =-\gamma \tilde{v}_{s c} ; \quad \gamma>0 \\
i_{f c}^{*} & =\frac{v_{b}}{\max \left\{\mathrm{v}_{\mathrm{fc}}, \mathrm{v}_{\mathrm{fcmin}}\right\}}\left(\frac{v_{b}^{*}}{R_{l}}-\alpha \tilde{v}_{s c}+C u_{i}\right) ; \quad \alpha>0 \\
i_{s c}^{*} & =-\alpha \tilde{v}_{b}
\end{aligned}
$$

Fig. (8) shows the system response. It shows that the DC bus and SC voltages reach the desired equilibrium point. Moreover, this controller allows the FC to have a smooth response during fast power demand of the load (8.e), which improves the state of health of the FC.

The tuning of non-linear controllers such as PBC is not obvious and trivial. To analyze the influence of the tuning parameters on the closed-loop system, more specifically on the FC current dynamics, some simulations have been done. In practice, increasing gamma leads to an under-damping closed-loop system, while increasing alpha gives for the FC current bigger slopes. After trial and error loops, a reasonable choice for $(\alpha, \gamma)$ is $(10,460)$. Instead of a manual tuning that not ensures an efficient control, IDA-PBC and loop optimization software could be used to ensure consistent results. 
Remark 3: All the stability properties of $x^{*}$ are preserved by adding to the IDA control an integral term. Here the proof is omitted due to the lack of place and can be found in the appendix 2 .

\section{Experimental results}

\subsection{Test bench description}

The hybrid test bench is presented in Fig. 9. The considered FC is a $46 \mathrm{~A} / 1200 \mathrm{~W}$ Nexa FC designed by Ballard. This latter is composed of 46 cells. The transient auxiliary source consists of two Maxwell SC modules associated in series: each module is built with the connection of six individual elements in series $[2.7 \mathrm{~V}, 350 \mathrm{~F}]$. This SCs device is interconnected to the DC bus using a chopper built with standard MOS modules and a switching frequency of the PWM set to $20 \mathrm{kHz}$ (Azib et al., 2010).

The hybrid power source is connected to a programmable electronic load (Höcherl \& Hackl, model ZS1806), which has a rated power of $1800 \mathrm{~W}(\mathrm{imax}=150 \mathrm{~A} / \mathrm{Vmax}=60 \mathrm{~V})$. This load emulates vehicle power consumption, and is directly monitored by the dSPACE DS1103 real-time board. Finally, table 1 summarize the electric characteristics of the on-board power sources.

The current inner control loops, which generate the duty cycle $\alpha_{1}$ and $\alpha_{2}$, have been implemented with digital PI controllers updated at $20 \mathrm{kHz}$. The voltage outer control loops have a sampling time equal to $2 \mathrm{KHz}$.

\subsection{Result analysis}

Experiments have been performed on the experimental setup to validate the previously explained control strategies. The reference DC bus voltage is set equal to $50 \mathrm{~V}$, and the load current varies between 0 and $15 \mathrm{~A}$ (this is equivalent to a variation of the load admittance $1 / R_{l}$ from 0 to $\left.0.3 \mathrm{~S}\right)$.

The case of an unknown parameter. Fig. (10.a) shows that the control ensures perfect control of the DC bus voltage, the SCs respond rapidly to fast load current transients in 
order to provide most of the power required by the load and to maintain the DC bus voltage at its reference value. This allows the $\mathrm{FC}$ to have a smooth response during fast power demand of the load (Fig. 10.e), which improves his state of health. Then gradually with the FC current increasing, the SCs discharge, characterized by the decrease of its voltage, vanishes to zero (see Fig. 10.e).

The SCs voltage is however not regulated to the reference value equal to $21 \mathrm{~V}$, and depends on the load power since the IDA-PBC controller assumes the load resistance as constant (here, the arbitrary admittance used in the controller equation is equal to $5 \mathrm{~A} / 50 \mathrm{~V}=$ 0.1S). Under these conditions, SCs provide too much energy during the power transition and SCs recharging is uncertain.

IDA-PBC controller + load resistance estimator. The latter experiment show that the SCs do not recover their equilibrium points while the load current increases, because of the inadequate value of the load resistance used in the controller. To overcome this problem, two solutions have been explored. First, the admittance $\left(Y_{l}=1 / R_{l}\right)$ of the load is estimated on-line according to Equ. (17).

Fig. 11 shows the whole system behavior where the load resistance estimate is used in the controller. This controller architecture also leads to a nearly zero static error of the SCs voltage. However, we can note that the SC voltage is not perfectly equal to its reference at steady state. This is due to the FC converter losses. Nevertheless, a low integral action or a converter-losses estimation could be added in a practical application to compensate for the converter losses.

IDA-PBC controller + integral action. The second experiment shown in Fig. (12) was carried out to validate the proposed strategy with an integral action. Note that the DC bus and $\mathrm{SC}$ voltages are well regulated in spite of the very fast dynamics of power demand. Each time the power load varies, SC current is positive (respectively negative) during an increase (respectively decrease) of the power load. In such a situation, the SC voltage continuously fluctuates around its constant reference value $v_{s c}^{*}$ set to $21 \mathrm{~V}$, as shown in Fig. (12.b). The experimental results confirm that the association of the FC and the SCs mitigates the FC 
current transient in order to increase the FC lifespan. Moreover, the experimental results are consistent with the simulation ones.

PI controller. For comparison, an experiment with PI controllers for the two outer-loops have been done based on the design proposed in (Azib et al., 2011), as shown on Fig. (13). Fig. (13.a) shows that the DC bus is well controlled due to greater SCs current compared to the previous results. Therefore, the fluctuation of the SCs voltage is more important.

Finally, simulation and experimental result show that the passivity-based controller and PI controller have almost the same performance. However, the new control law based on passivity ensures a locally asymptotic stability of the whole closed-loop system that is not demonstrated for PI controllers and these latter have 4 tuning parameters $\left(K p_{f c}, K i_{f c}, K p_{s c}, K i_{s c}\right)$ compared to only 2 tuning parameters $\left((\alpha, \gamma)\right.$ or $\left.\left(\alpha, K_{R l}\right)\right)$ for the passivity-based controller, which makes the implementation of the IDA-PBC on a real-time system easier.

\section{Conclusion}

In this paper, a new control strategy to manage the energy between two power sources, namely a hydrogen fuel cell and supercapacitors has been discussed. This new control law based on passivity ensures a locally asymptotic stability of the whole closed-loop system, while reducing the load stress on the stack power transients. In addition, this outer voltage controller has only 2 tuning parameters $\left((\alpha, \gamma)\right.$ or $\left.\left(\alpha, K_{R l}\right)\right)$, which makes the implementation on a real-time system easier.

As the controller needs the information on the load resistance, the paper has proposed two alternative solutions : to add an integral action or a load resistance estimator. In both cases the FC dynamic can be easily tuned while the SCs state of charge is well regulated in steady state. Simulation and experimental results are consistent, and the controller performances validate the proposal.

As mentioned previously in section II, passivity based controllers have been proposed for similar systems where the converter is directly control. The lack of a separate current control loop makes it difficult to achieve current limitation which is mandatory in industrial 
applications for hardware protection. It means that the current is measured but not controlled. The proposed PBC with cascaded loops protects the sources, the converters and the load as regular controllers. Finally, the controller leads to a general non-linear PI controller that extends the theory with regular PI controllers and gives confidence in the stability with almost the same experimental performances as regular controller.

It is difficult for the fuel flow to follow the current steps, which decreases the lifespan of the FC. Therefore, synchronization between the FC controller, the FC converter and the $\mathrm{SC}$ converter is mandatory. In order to extend this work, a future study could investigate the introduction of a more complicated modelling of the FC, i.e. adding the air compressor dynamic and studing its impact on the controller design and system performances. It follows that local or global design control of each components needs further investigations.

Finally, the parallelism of N-sources leads to a redundancy and therefore improves the reliability and efficiency of the whole system (Malaizé and Dib, 2011; De Bernardinis et al., 2012). Challenging control issues could investigate the generalization of this works to N-parallel connected sources with different or same characteristics leading to switchingcontroller according the state of charge $(\mathrm{SoC})$ and state of health $(\mathrm{SoH})$ of each source.

\section{References}

Arce, A., del Real, A.J., \& Bordons, C. (2009), "MPC for battery/fuel cell hybrid vehicles including fuel cell dynamics and bettery performance improvement," Journal of process control, 19, 1289-1304.

Azib, T., Bethoux, O., Remy, G., \& Marchand, C. (2009a), "Structure and Control Strategy for a Parallel Hybrid Fuel Cell/Supercapacitors Power Source," IEEE VPPC'09, Dearborn, Michigan, 1858-1863.

Azib, T., Bethoux, O., Marchand, C., \& Berthelot, E. (2009b), "Supercapacitors for Power Assistance in Hybrid Power Source with Fuel Cell," IEEE Industrial Electronics Society Conference IECON'09, Porto, Portugal, 3747-3752.

Azib, T., Bethoux, O., Remy, G., \& Marchand, C. (2010), "An innovative control strategy of a single converter for hybrid fuel cell/supercapacitors power source," IEEE Transactions on Industrial Electronics, $57(2), 4024-4031$.

Azib, T., Bethoux, O., Remy, G., \& Marchand, C. (2011), "Saturation Management of a Controlled FuelCell/Ultracapacitor Hybrid Vehicle," IEEE Transactions on Vehicular Technology, 60(9), 4127 -4138. 
Becherif, M. (2006), "Passivity-based control of hybrid sources : fuel cell and battery," $11^{\text {th }}$ IFAC Symposium on Control in Transportation Systems, The Netherlands.

Brahma, A., Guezennec, Y., \& Rizzoni, G. (2000), "Optimal energy management in series hybrid electric vehicles," American Control Conference, 1(6), 60-64.

Cacciato, M., Caricchi, F., Giuhlii, F., \& Santini, E. (2004), "A critical evaluation and design of bi-directional DC/DC converters for supercapacitors interfacing in fuel cell applications," IEEE Industry Applications Conference (IAS), 2, 1127-1133.

Caux, S., Lachaize, J., Fadel, M., Shott, P., \& Nicod, L. (2005), "Modelling and control of a Fuel Cell System and Storage Elements in transport applications," Journal of Process Control, 15, 481-491.

Cecati, C., Dell'Aquila, A., Liserre, M., \& Monopoli, V.G. (2003) "A passivity-based multilevel active rectifier with adaptive compensation for traction applications", IEEE Transactions on Industry Applications, $39,(5), 1404-1413$.

Corbo, P., Migliardinia, F., \& Veneri, O. (2009), "PEFC stacks as power sources for hybrid propulsion systems," International Journal of Hydrogen Energy, 34(10), 4635-4644.

Yousfi-Steiner, N. Moçotéguy, Ph., Candusso, D., Hissel, D., "A review on polymer electrolyte membrane fuel cell catalyst degradation and starvation issues: Causes, consequences and diagnostic for mitigation," Journal of Power Sources, 194(1), 130-145.

Davat, B., Astier, S., Azib, T., Bethoux, O., \& all (2009), "Fuel cell-based hybrid systems," Electromotion - EPE chapter 'electric drives', Lille, France, 1-11.

Donaire, A., \& Junco, S. (2009) "On the addition of integral action to port-controlled Hamiltonian systems," Automatica, 45(8), 1910-1916.

Hissel, D., Turpin, C., Astier, S., Boulon, L., \& all (2008), "A review on existing modeling methodologies for PEM fuel cell systems," Fundamentals and developments of fuel cells cenference, FDFC, Nancy, France, $1-30$.

Isidori, A. (1995) "Nonlinear control systems," Springer, Third edition.

Jeltsema, D., \& Scherpen, J.M.A. (2003) "A dual relation between port-Hamiltonian systems and the Brayton-Moser equations for nonlinear switched RLC circuits," Automatica, 39(6), 969-979.

Jiang, Z., Gao, L., Blackwelder, M.J., \& Dougal, R.A. (2004), "Design and experimental tests of control strategies for active hybrid fuel cell/battery power sources," Journal of Power Sources, 130, 163-171.

Kisacikoglu, M.C., Uzunoglu, M., \& Alam, M.S. (2009), "Load sharing using fuzzy logic control in a fuel cell/ultracapacitor hybrid vehicule," International Journal of Hydrogen Energy, 34, 1497-1507.

Kokotovic, P., Khalil, H., \& O'Reilly, J., (1986), "Singular perturbation methods in control: Analysis and design," Academic Press, New-York.

LaSalle, J.P. (1960), "Some extensions of Lyapunov's second method," IRE Transactions on Circuit Theory, 


\section{$7,520-527$.}

Marino, R. (1985), "High-gain feedback in non-linear control system," International Journal of Control, 42, 1369-1385.

Martinez, J.S., Hissel, D., Pera, M-C., \& Amiet, M. (2011), "Practical Control Structure and Energy Management of a Testbed Hybrid Electric Vehicle," IEEE Transactions on Vehicular Technology, 60(9), 4139-4152.

Ortega, R., van der Schaft, A., Maschke, B., \& Escobar, G. (2002) "Interconnection and damping assignment passivity-based control of port-controlled Hamiltonian systems," Automatica, 38(4), 585-596.

Ortega, R., \& Garcia-Canseco, E. (2004) "Interconnection and damping assignment passivity-based control : a survey," European Journal of control, 10, 432-450.

Ortega, R., van der Schaft, A., Castanos, F., \& Astolfi, A. (2008) "Control by interconnection and standard passivity-based control of Port-Hamiltonian systems," IEEE Transactions on Automatic Control, 53(11), 2527-2542.

Paladini, V., Donateo, T., de Risi, A., \& Laforgia, D. (2007), "Super-capacitors fuel-cell hybrid electric vehicle optimization and control strategy development," Energy Conversion and Management, 48(11), 3001-3008.

Panteley, E., \& Loria, A. (1998) "On global uniform asymptotic stability of nonlinear time varying systems in cascade," Syst. Contr. Lett, 33(2), 131-138.

Pukrushpan, J.T., Peng, H., \& Stefanopoulou, A.G. (2004) "control-oriented modeling and analysis for automotive fuel cell systems," Transactions on ASME, 26, 14-25.

Rodatz, P., Paganelli, G., Sciarretta, A., \& Guzzella, L. (2005) "Optimal power management of an experimental fuel cell/supercapacitor-powered hybrid vehicle," Control Engineering Practice, 13(1), 41-53.

Thounthong, P., Rael, S., \& Davat, B. (2009), "Energy management of fuel cell/battery/supercapacitor hybrid power source for vehicle applications," Journal of Power Sources, 193(1), 376-385.

Thounthong, P., Rael, S., Davat, B,\& Sethakul, P. (2009b), "Fuel cell high-power applications," IEEE Industrial Electronics Magazine, 3(1), 32-46.

Tikhonov, A.N., Vasil'eva, A.B., \& Volosov, V.M. (1970) "Ordinary differential equations," E. Roubine, editor, Mathematics Applied to Physics, pp. 162-228, Springer-Verlag, New York.

Vahidi, A., Stefanopoulou, A., \& Peng, H. (2006), "Current management in a hybrid fuel cell power system : a model-predictive control approach," IEEE Transactions on Control Systems Technology, 14(6).

Van der Schaft, A.J. (1996) "L2-Gain and Passivity Techniques in Nonlinear Control," Springer-Verlag, Berlin.

Vasil'eva, A.B. (1963), "Asymptotic behavior of solutions to incertain problems involving nonlinear differential equations containing a small parameter multipling the highest derivatives" Russian Math. Surveys 
$18,13-18$.

Wahdame, B., Candusso, D., François, X., Harel, F., Péra, M.C., Hissel, D., \& Kauffmann, J.M. (2008), "Comparison between two PEM fuel cell durability tests performed at constant current under solicitations linked to transport mission profile," International Journal of Hydrogen Energy, 33(14), 3829-3836.

Weiss, L., Mathis, M., \& Trajkovic, L. (1998) “A generalization of Brayton-Moser's mixed potential function, IEEE Transactions on Circuits and Systems-I, 45(4), 423-427.

Zandi, M., Payman, A., Martin, J.P., Pierfederici, S., Davat, B., \& Meibody-Tabar, F. (2011), "Energy Management of a Fuel Cell/Supercapacitor/Battery Power Source for Electric Vehicular Applications," IEEE Transactions on Vehicular Technology, 60(2), 433-443.

Zhou, H., Khambadkone, A.M., \& Kong, X. (2009), "Passivity-Based Control for an Interleaved Current-Fed Full-Bridge Converter With a Wide Operating Range Using the Brayton-Moser Form," IEEE Transactions on Power Electronics, 24(9), 2047-2056.

Malaizé, J.,\& Dib, W., "Control of N-parallel Connected Boost Converters Feeding a Constant Power Load: an Automotive Case Study," IEEE Industrial Electronics Society Conference, IECON'11, Melbourne, Australia, 528-533.

De Bernardinis, A., Frappé, E., Béthoux, O., Marchand, C.,\& Coquery, G. (2012), "Multi-port power converter for segmented PEM fuel cell in transport application," European Physical Journal - Applied Physics, 58, 20901-p1-p15.

Konig, O., Gregorcic, G.,\& Jakubek, S. (2013), "Model predictive control of a DC-DC converter for battery emulation," Control Engineering Practice, 21, 428-440. 


\section{Appendix 1: Stability analysis with an integral action}

Proposition 1: Consider the PCH system (11) in closed-loop with the controller (1213). Then, all stability properties of $x^{*}$ are preserved by adding to the IDA control (12-13) an integral term as shown in (18)-(20).

Proof. The extended IDA (14) associated with the controller (18)-(20) takes the PCH form

$$
\left[\begin{array}{c}
\dot{\tilde{x}} \\
\dot{x}_{c}
\end{array}\right]=\left[\begin{array}{cc}
\mathcal{J}_{d}-\mathcal{R}_{d} & K_{I}^{T} \\
-K_{I} & 0
\end{array}\right]\left[\begin{array}{c}
\partial H_{d e} / \partial \tilde{x} \\
\partial H_{d e} / \partial x_{c}
\end{array}\right]
$$

where $H_{d e}=H_{d}+\left(x_{c}^{T} K_{I}^{-1} x_{c}\right) / 2$ qualifies now as Lyapunov function with $K_{I}=\left[\begin{array}{lll}0 \gamma / C_{s c} & 0\end{array}\right]$. Then, it follows that all the stability properties are preserved.

\section{Appendix 2: Stability analysis with a load estimator}

The proof of the global stability of the outer-loop composed of the controller, the estimator and reduced-order electrical system is established invoking a theorem on stability of cascaded systems stated in (Panteley and Loria, 1998).

Proposition 2: Consider the hybrid system (10) in closed-loop with the control law (12-13) where $R_{l}$ is replaced by $\hat{R}_{l}=1 / \hat{Y}_{l}$ generated by (17). For all initial conditions, $\lim _{t \rightarrow \infty} x(t)=x^{*}$ is guaranteed.

Proof. First, the load estimator (17) is an autonomous linear system, which is globally uniformaly asymptotically stable for all positive gain $K_{r l}$. Thus, the estimation error decay asymptotically to zero.

Secondly, let us define the estimation error $\tilde{\tau}_{l}=\hat{Y}_{l}-Y_{l}$, and write the closed-loop system in the following form:

$$
\dot{\tilde{x}}=\left[\mathcal{J}_{d}(x)-\mathcal{R}_{d}(x)\right] \nabla H_{d}(x)+\varphi(x) \tilde{Y}_{l}
$$

with $\varphi(x)=\left[\begin{array}{ccc}\frac{x_{1}^{*}}{C} & 0 & 0\end{array}\right]^{t}$ 
The overall error dynamics is a cascade composition like the ones studied in [(Panteley and Loria, 1998),Th.2]. The nominal part of the first subsystem (21), namely $\dot{\tilde{x}}=\left[\mathcal{J}_{d}(x)-\right.$ $\left.\mathcal{R}_{d}(x)\right] \nabla H_{d}(x)$, is globally uniformaly asymptotically stable. Further, the Lyapunov function $H_{d}$ is a quadratic function, thus it satisfies the bounds

$$
\begin{array}{rlrl}
\left\|\frac{\partial H_{d}}{\partial x}(x)\right\|\|x\| \leq c_{1} H_{d}(x), & & \forall\|x\| \geq \eta \\
\left\|\frac{\partial H_{d}}{\partial x}(x)\right\| \leq c_{2}, & \forall\|x\| \leq \eta
\end{array}
$$

where $c_{1}, c_{2}, \eta>0$. This is condition (A.1) of [(Panteley and Loria, 1998),Th.1]. Second, from inspection of the definitions of $\varphi(x)$ above, and the fact that $\tilde{Y}_{l}$ is bounded, then the interconnection term satisfies the bound $\|\varphi(x)\| \leq c_{3}$ for $c_{3}>0$, as required by condition (A.2). Finally, the last condition of the theorem, requiring that the second subsystem in (21) be globally uniformaly asymptotically stable and that its response to initial condition be absolutely integrable, is satisfied since the subsystem (17) is asymptotically stable. This completes the proof of our proposition.

\section{Appendix 3:}

In our work, the load has been modeled by a resistance circuit. However, without loss of generality, is it possible to consider a current disturbance $i_{l}(t)=P(t) / v_{b}(t)$ that lead to the controller (Konig, Gregorcic and Jakubek, 2013):

$$
\begin{aligned}
i_{f c}^{*} & =\frac{v_{b}}{\max \left\{\mathrm{v}_{\mathrm{fc}}, \mathrm{v}_{\mathrm{fcmin}}\right\}}\left(\hat{i}_{l}-\alpha \tilde{v}_{s c}\right) ; \quad \alpha>0 \\
i_{s c}^{*} & =-\alpha \tilde{v}_{b}
\end{aligned}
$$

where $\hat{i}_{l}$ is the output of a low-pass filter with measurement $i_{l}$ as input. The low-pass filter has the same objective as the load estimator. It is here to smooth the FC current and avoid peak FC current if the measured load current has been used in controller (22). 


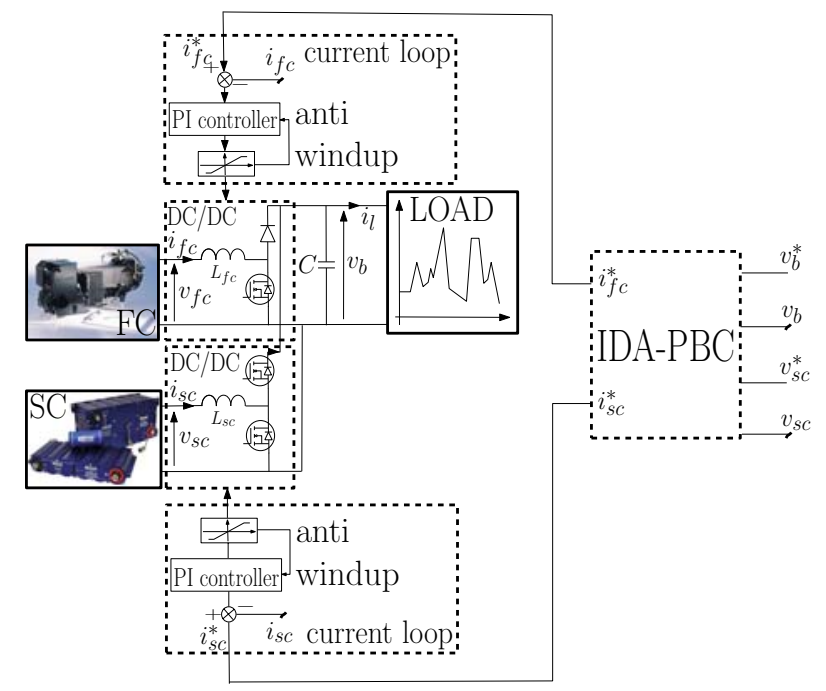

Figure 2: IDA-PBC structure.

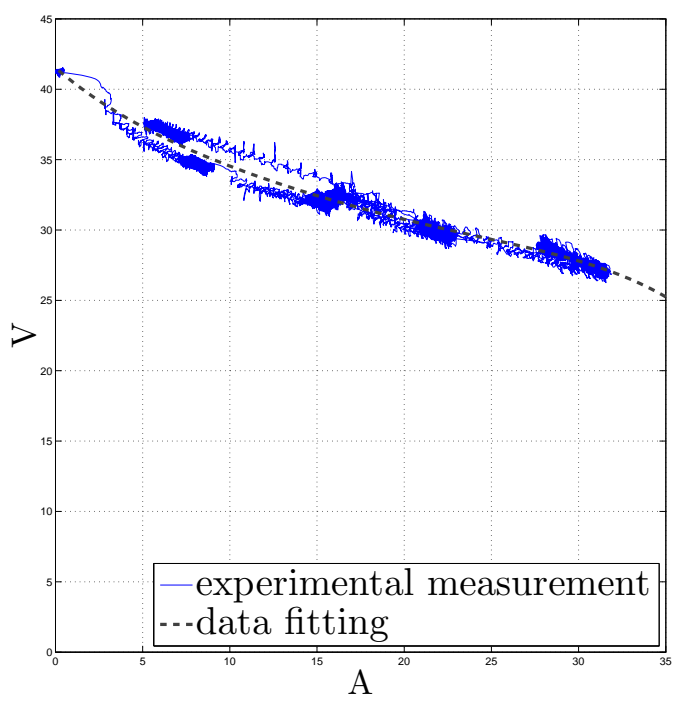

Figure 3: Fuel cell voltage vs current. 


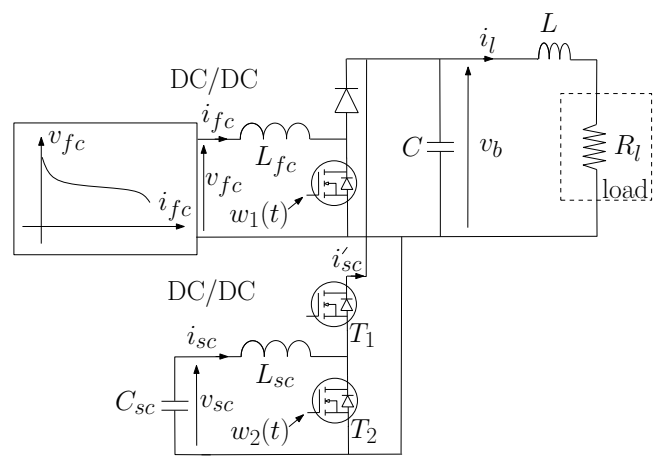

Figure 4: DC bus and load model.

(a) bus voltage $v_{b}$

(b) SCs voltage $v_{s c}$

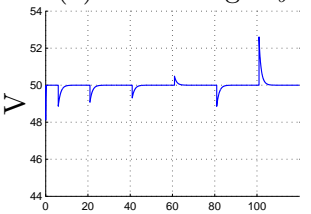

(c) load current $i_{L}$
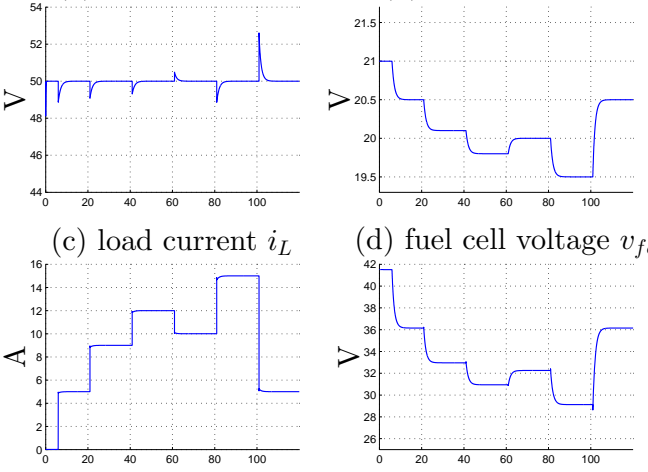

(d) fuel cell voltage $v_{f c}$

(e) fuel cell current $i_{f c}$
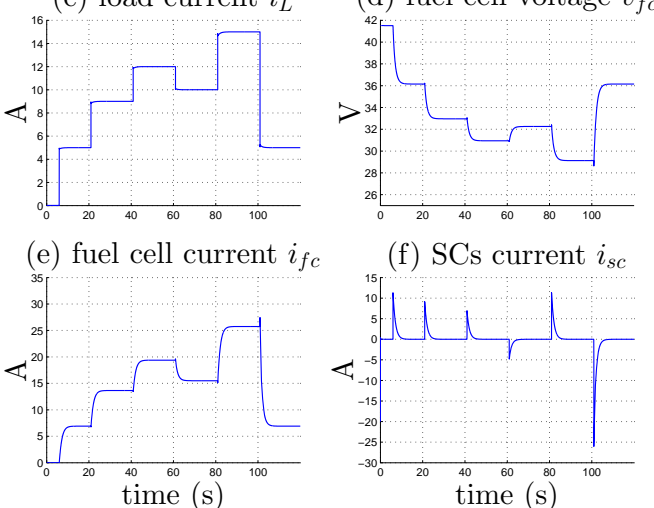

Figure 5: Simulation result with the resistance as unknown parameters $(\alpha=10)$. 


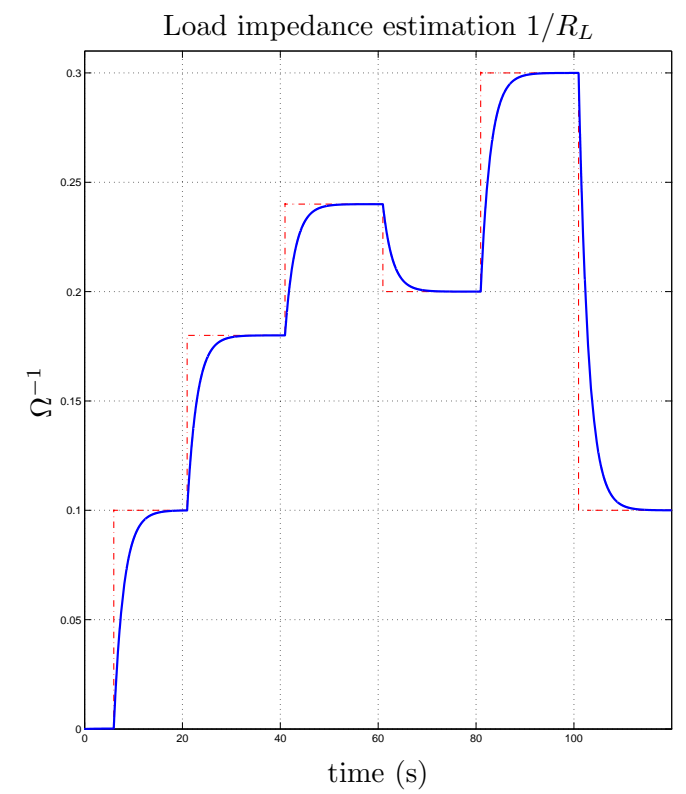

Figure 6: Simulation result of the load admittance estimation.

(a) bus voltage $v_{b}$

(b) SCs voltage $v_{s c}$
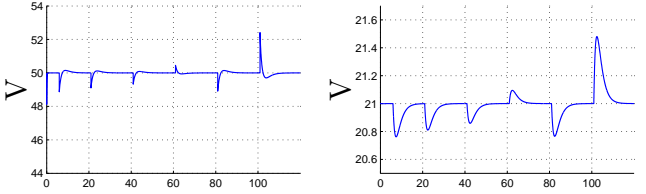

(c) load current $i_{L}$

(d) fuel cell voltage $v_{f c}$
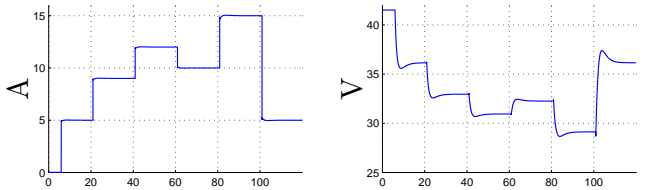

(e) fuel cell current $i_{f c}$

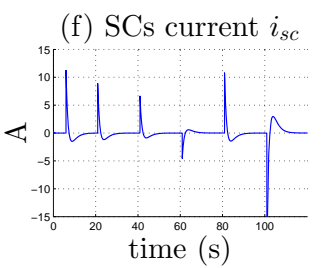

Figure 7: Simulation with the load resistance estimator $\left(\alpha=10, K_{R l}=0.5\right)$. 
(a) bus voltage $v_{b}$

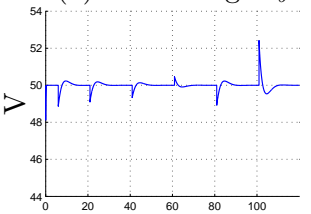

(c) load current $i_{L}$

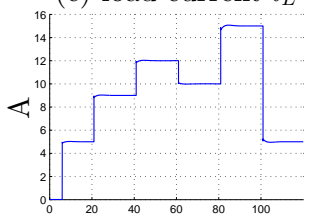

(e) fuel cell current $i_{f c}$

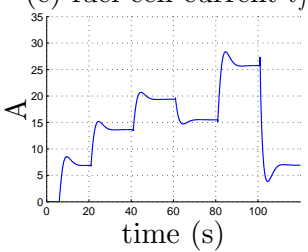

(b) SCs voltage $v_{s c}$

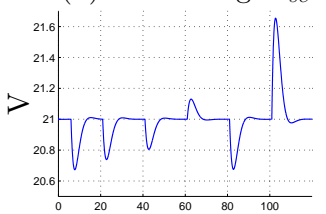

(d) fuel cell voltage $v_{f c}$
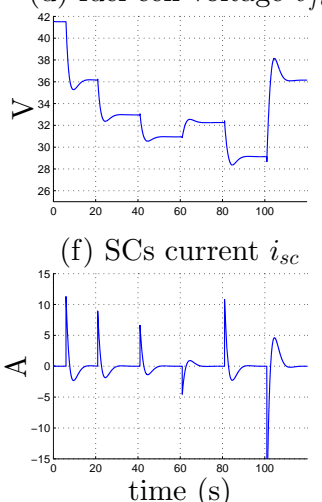

Figure 8: Simulation result with an integral action $(\alpha=10, \gamma=460)$.

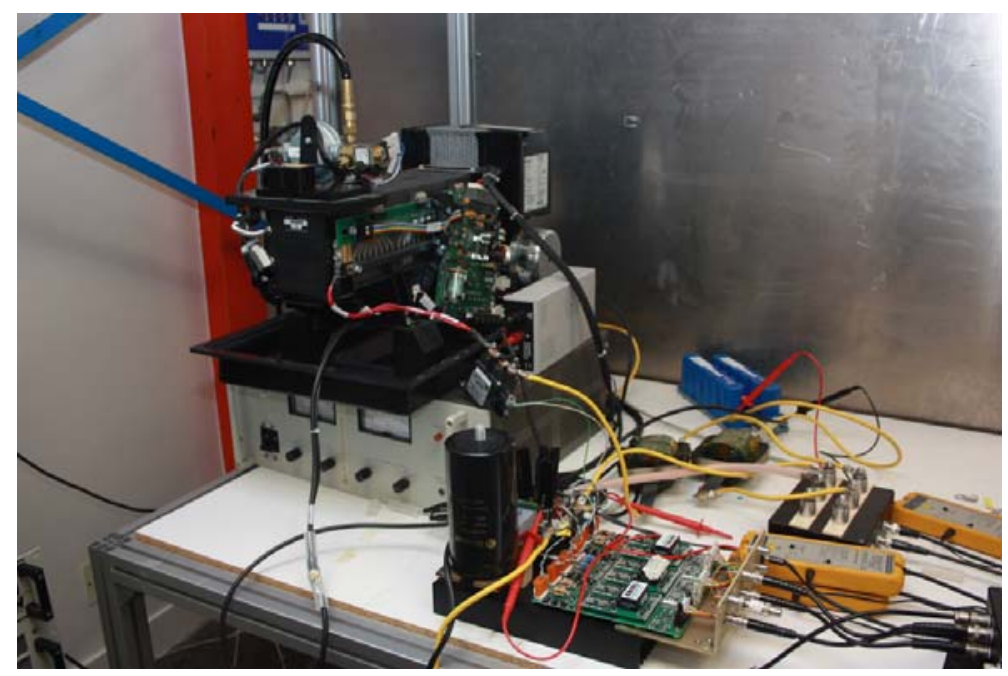

Figure 9: Experimental test bench. 
(a) bus voltage $v_{b}$

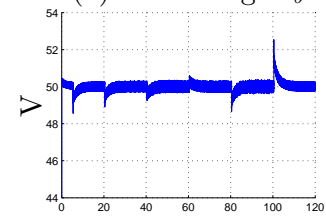

(c) load current $i_{L}$

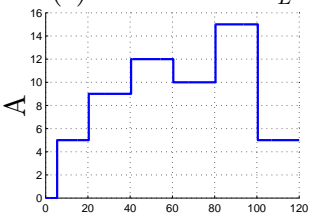

(e) fuel cell current $i_{f c}$

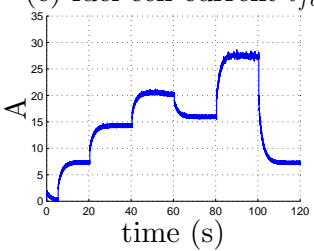

(b) SCs voltage $v_{s c}$

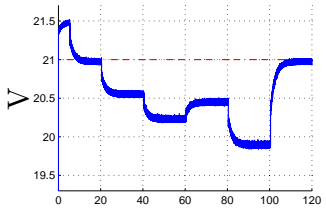

(d) fuel cell voltage $v_{f c}$

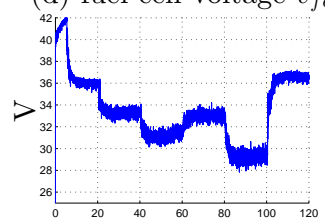

(f) SCs current $i_{s c}$

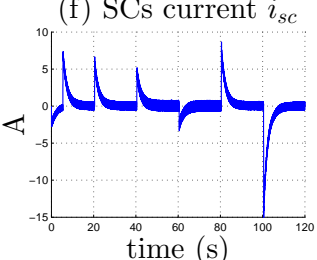

Figure 10: Experimental result during a step load without an integral action or a load estimator $(\alpha=10$, $\gamma=0)$.

(a) bus voltage $v_{b}$

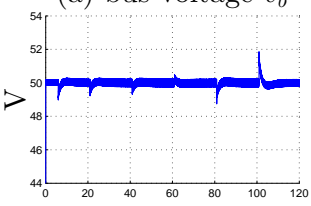

(c) load current $i_{L}$

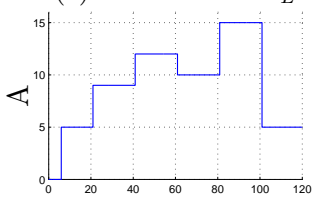

(e) fuel cell current $i_{f c}$

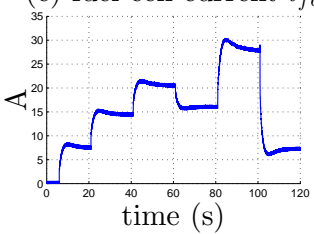

(b) SCs voltage $v_{s c}$

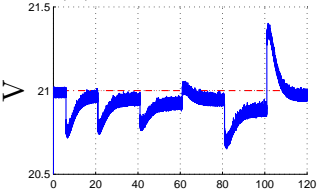

(d) fuel cell voltage $v_{f c}$
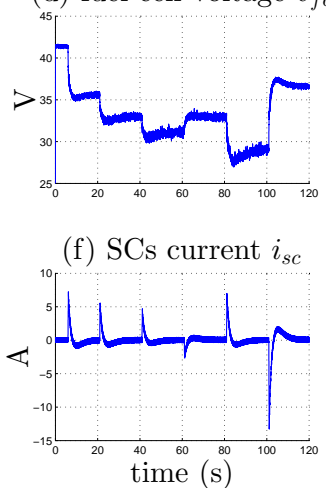

Figure 11: Experimental result with the load resistance estimation $\left(\alpha=10, K_{R l}=0.5\right)$. 
(a) bus voltage $v_{b}$

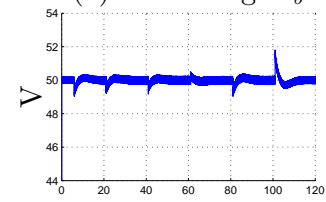

(c) load current $i_{L}$

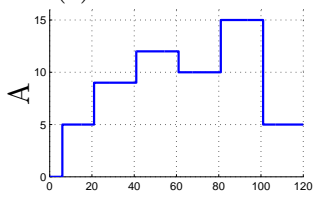

(e) fuel cell current $i_{f c}$

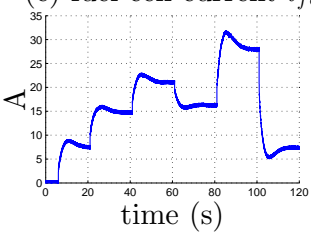

(b) SCs voltage $v_{s c}$

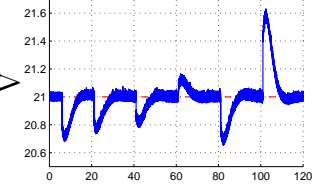

(d) fuel cell voltage $v_{f c}$
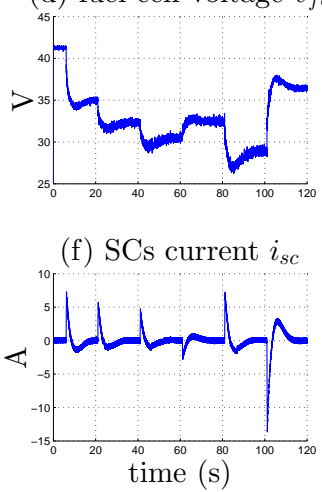

Figure 12: Experimental result during a step load with an integral action $(\alpha=10, \gamma=460)$.

(a) bus voltage $v_{b}$

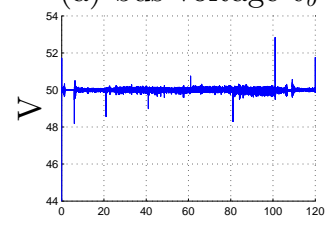

(c) load current $i_{L}$

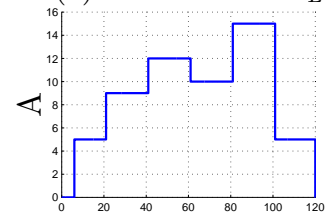

(e) fuel cell current $i_{f c}$ (b) SCs voltage $v_{s c}$

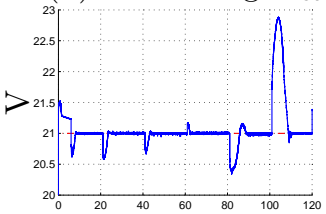

(d) fuel cell voltage $v_{f c}$

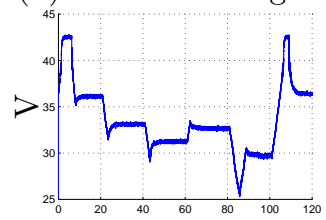

(e) SCs current $i_{s c}$

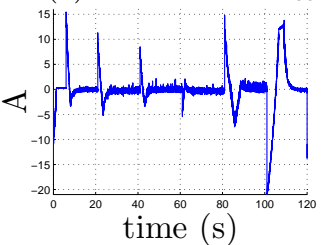

Figure 13: Experimental result during a step load with PI controllers. 
Table 1: Electric characteristics of the hybrid system.

\begin{tabular}{|c|c|c|c|}
\hline \multicolumn{4}{|l|}{ Fuel cell parameters } \\
\hline Open circuit voltage $\mathrm{E}$ & $45 \mathrm{~V}$ & $v_{f c m i n}$ & $26 \mathrm{~V}$ \\
\hline Rated voltage & $26 \mathrm{~V}$ & Rated current & $46 \mathrm{~A}$ \\
\hline \multicolumn{4}{|c|}{ Supercapacitors parameters } \\
\hline Capacitance & $125 \mathrm{~F}$ & $v_{s c}^{*}$ & $21 \mathrm{~V}$ \\
\hline Rated voltage & $30 \mathrm{~V}$ & Rated current & $200 \mathrm{~A}$ \\
\hline \multicolumn{4}{|l|}{ Electric load parameters } \\
\hline Rated voltage & $60 \mathrm{~V}$ & Rated current & $150 \mathrm{~A}$ \\
\hline Rated power & $1800 \mathrm{~W}$ & & \\
\hline \multicolumn{4}{|c|}{ Inductance and capacity parameters } \\
\hline$L_{f c}$ inductance & $200 \mu \mathrm{H}$ & $L_{s c}$ inductance & $100 \mu \mathrm{H}$ \\
\hline Rated current $L_{f c}$ & $100 \mathrm{~A}$ & Rated current $L_{s c}$ & $150 \mathrm{~A}$ \\
\hline Capacity $C$ & $9 \mathrm{mF}$ & Inductance $L$ & $1 \mathrm{mH}$ \\
\hline$v_{b}^{*}$ & $50 \mathrm{~V}$ & & \\
\hline \multicolumn{4}{|l|}{ Control parameters } \\
\hline$K p_{f c}$ & 0.030 & $K i_{f c}$ & 30 \\
\hline$K p_{s c}$ & 0.030 & $K i_{s c}$ & 30 \\
\hline$\alpha$ & 10 & $\gamma$ & 460 \\
\hline$K_{R l}$ & 0.5 & & \\
\hline
\end{tabular}

